\title{
Role of KCNQ1 in the Cell Swelling-Induced Enhancement of the Slowly Activating Delayed Rectifier K+ Current
}

\author{
Tomoyuki KUBOTA, Minoru HORIE, Makoto TAKANO*, Hidetada YOSHIDA, \\ Hideo OTANI, and Shigetake SASAYAMA \\ Departments of Cardiovascular Medicine, and \\ * Cellular and Molecular Physiology, Kyoto University Graduate School \\ of Medicine, Kyoto, 606-8057 Japan
}

\begin{abstract}
Cell swelling enhances a slowly activating delayed rectifier $\mathrm{K}^{+}$current $\left(l_{\mathrm{Ks}}\right)$ in cardiac cells. This investigation was undertaken to determine which of the two structural units reconstituting the $I_{\mathrm{Ks}}$ channel, KCNQ1 (KvLQT1) and KCNE1 (minK/IsK), plays a key role in the cell swellinginduced $I_{\mathrm{Ks}}$ enhancement and to dissect a possible involvement of tyrosine phosphorylation therein. KCNQ1 was transiently expressed alone or together with KCNE1 in a heterologous mammalian cell line. Two distinct whole-cell membrane currents were separately observed during the exposure of transfected cells to various degrees of hyposmotic solutions. A hyposmotic challenge ( 0.7 times control osmolarity) resulted in about a twofold increase not only in the heteromeric KCNQ1/KCNE1, but also in the homomeric KCNQ1 channel currents. There was no
\end{abstract}

significant difference in the incremental ratio of current amplitude in response to hyposmotic stress between the two KCNQ1-related currents, and the cells expressing the heteromeric channels swelled less than those with the homomeric channels or without the exogenous ones. The cell swelling-induced $l_{\mathrm{Ks}}$ enhancement was not affected by a protein tyrosine kinase (PTK) inhibitor, by genistein $(50 \mu \mathrm{M})$, or by an inhibitor of phosphotyrosine phosphatase (PTP), orthovanadate $(500 \mu \mathrm{M})$, or a nonhydrolyzable ATP analogue, AMP-PNP $(5 \mathrm{~mm})$. Taken together, it is very likely that KCNQ1 might primarily participate in the $I_{\mathrm{Ks}}$ enhancement by osmotic cell swelling. The obligatory dependence of the $l_{\mathrm{Ks}}$ augmentation on PTK activity remained to be demonstrated, at least, in this expression system. [Japanese Journal of Physiology, 52, 31-39, 2002]

Key words: cell swelling, slowly activating delayed rectifier $\mathrm{K}^{+}$current $\left(I_{\mathrm{Ks}}\right), \mathrm{KCNQ} 1, \mathrm{KCNE} 1$, tyrosine phosphorylation.

Cell swelling alters the electrophysiological properties in cardiac myocytes [1]. Previous studies reported that an exposure of cardiac cells to anisosmolar solutions led to the shortening of action potential duration (APD) in bullfrog and guinea pig ventricles [2, 3]. Although many ion conductances contribute to cardiac action potentials, APD is pivotally determined by a variety of transient or sustained $\mathrm{K}^{+}$currents [4]. The ionic basis of the changes in APD, however, has yet to be fully understood.

To date, experimental studies using patch-clamp techniques have shown that hyposmotically induced cell swelling in isolated cardiomyocytes modulates several different ion channels and transporters, including the swelling-induced $\mathrm{Cl}^{-}$channel [5], the $\mathrm{K}_{\text {ATP }}$ channel [6], the $\mathrm{Na}^{+} / \mathrm{K}^{+}$pump [7], and the $\mathrm{Na}^{+} / \mathrm{Ca}^{2+}$ exchanger [8]. In particular, present interest in the cell swelling-induced enhancement of the delayed rectifier $\mathrm{K}^{+}$current $\left(I_{\mathrm{K}}\right)$ was triggered from the observations of Sasaki et al. $[9,10]$ that in guinea pig ventricular myocytes, hyposmotic stress stimulates its activity. On the basis of the kinetic and pharmacological properties of $I_{\mathrm{K}}$, it can be separated into two components in different cardiomyocytes of various species: a rapidly 
activating component $\left(I_{\mathrm{Kr}}\right)$ and a more slowly activating component $\left(I_{\mathrm{Ks}}\right)[11,12]$. In this connection, Rees et al. have elegantly demonstrated that in guinea pig ventricular myocytes, $I_{\mathrm{Ks}}$ is potentiated, but $I_{\mathrm{Kr}}$ is inhibited by cell swelling, indicating that it has differential effects on these two components [13].

Recently, a pioneering study that defined the genetic defects behind the long QT syndrome type 1 (LQT1) has facilitated the identification of the molecules responsible for $I_{\mathrm{Ks}}$ [14]. It is now accepted that the two structurally different membrane proteins, the pore-forming $\alpha$-subunit KCNQ1 and the regulatory $\beta$ subunit KCNE1, reconstitute the $I_{\mathrm{Ks}}$ channel $[15,16]$. Thus the present study was initiated to determine which of the two distinct subunits plays a key role in the cell swelling-induced $I_{\mathrm{Ks}}$ enhancement.

Given the range of regulatory factors that can modulate the activity of $I_{\mathrm{Ks}}$, including protein kinase A (PKA), protein kinase $\mathrm{C}$ (PKC) [17], and intracellular $\mathrm{Ca}^{2+}$ [18], little has been unraveled about underlying mechanisms, whereby osmotic cell swelling activates the $I_{\mathrm{Ks}}$ channel. Noticeably, Zhou et al. suggested that in canine ventricular myocytes, protein tyrosine kinase (PTK) participated in the $I_{\mathrm{Ks}}$ enhancement by cell swelling [19], though it remains unanswered whether the channel itself or an intermediate substrate in the regulatory pathway is phosphorylated. Therefore we further attempt to dissect a possible involvement of tyrosine phosphorylation and dephosphorylation as the major mechanism in the $I_{\mathrm{ks}}$ augmentation.

\section{METHODS}

Expression constructs for KCNQ1 and KCNE1. Both expression vectors of pCI-KCNQ1, which contains a full-length human KCNQ1 cDNA (GenBank AF000571) in pCI vector (Promega, Madison, WI, USA), and pIRES/CD8-KCNE1, which carries a human KCNE1 cDNA (GenBank M26685) in pIRES/CD8 vector, were generously provided by Dr. J. Barhanin (Institut de Pharmacologie Moleculaire et Cellulaire, CNRS, France). The restriction fragment NheI-XmaI containing the KCNQ1 coding region was subcloned into pIRES2/EGFP plasmid (Clontech, Palo Alto, CA, USA) for its sole expression study.

Cell culture and electrophysiological recordings. COS7 cells were seeded at a density of $3 \times 10^{4}$ cells per $35 \mathrm{~mm}$ petri dish, then cultured for 12 to $24 \mathrm{~h}$ before transfection in Dulbecco's modified Eagle medium (Gibco-BRL, Rockville, MD, USA) supplemented with $10 \%$ fetal bovine serum (GibcoBRL). The cells were transiently transfected with KCNQ1 alone or together with KCNE1, using the
LipofectAMINE method according to the manufacturer's instructions (Gibco-BRL). The amount of the plasmids employed here was $1 \mu \mathrm{g}$ of pIRES2/EGFPKCNQ1 for the homomeric KCNQ1 channel and $1 \mu \mathrm{g}$ of pIRES/CD8-KCNE1 for the reconstitution of the heteromeric KCNQ1/KCNE1 $\left(I_{\mathrm{Ks}}\right)$ channel. For electrophysiological experiments 24 to $48 \mathrm{~h}$ later, transfected cells were easily visualized with fluorescence in expression experiments for KCNQ1 alone and further selected by decoration with anti-CD8 antibodycoated beads (Dynabeads CD8, Dynal Biotech., Norway) in coexpression with KCNE1.

The tight-seal, whole-cell, voltage-clamp configuration of the patch-clamp technique was used for electrophysiological recordings. Pipettes were prepared from thin-walled bolosilicate glass capillaries (Narishige, Tokyo, Japan) on a Narishige PP83 electrode puller (Narishige). The resistances of the pipettes ranged from 3.0 to $5.0 \mathrm{M} \Omega$ when filled with the pipette solutions described below. A tight seal between the cell membrane and the pipette tip (seal resistance, $>5 \mathrm{G} \Omega$ ) was achieved by a gradual application of light suction. After the formation of a tight seal, the membrane under the pipette tip was ruptured by a further increase in suction, to form the whole cell-recording configuration. An Axopatch 200A amplifier (Axon Instruments, Foster City, CA, USA) was used for voltage clamping. Commercial software from Axon Instruments (pCLAMP 6) was used for the generation of voltage-clamp protocols, data acquisition, and data analysis. Data were filtered at $1 \mathrm{kHz}$ by a filter incorporated in the Axopatch 200A amplifier and stored on the hard disk of an IBM-compatible computer (IBM, Tokyo, Japan) for later analysis. The liquid junction potential between the pipette solution and the external one was not corrected for any membrane potential recordings. An exchange of external solutions was performed by switching the perfusates at the inlet of the recording chamber, and the time for a total exchange of solutions in the chamber was $\sim 1 \mathrm{~min}$. All experiments were conducted at $37 \pm 1^{\circ} \mathrm{C}$.

During these experiments, the patch-clamped $\operatorname{COS} 7$ cells displayed a concomitant increase in background membrane conductance that was manifested as an outward shift of the instantaneous current level during a hyposmotic challenge. Plasmid control-transfected cells produced only a small amplitude of the background conductance in response to depolarizing voltage pulses under the control condition, and superfusion with hyposmotic solutions was accompanied by a gradual increase in a time-independent, outward conductance on step depolarization. Because it was negligibly small in current amplitude $(\sim 0.3 \mathrm{nA})$, in this 
study the changes of those time-dependent currents were estimated as the difference in current amplitude between their values measured at the start and at the end of depolarizing pulses.

The changes of the cell volume during the osmotic cell swelling were approximated by geometric measurements [20]. According to previous studies [20, 21], we measured the cell area under the microscope as an approximation of the cell volume. The image of the single transfected cell under the whole cell voltage clamp was recorded with a video recorder, and the cell area was measured on a computer by the use of software of the NIH image (NIH, Bethesda, MD, USA).

Solutions and drugs. The composition of the $70 \%$ hyposmotic solution was (in $\mathrm{mM}$ ) $\mathrm{NaCl} 100, \mathrm{KCl}$ 5.4, $\mathrm{CaCl}_{2} 2, \mathrm{MgCl}_{2}$ 1, and HEPES 5, and the $\mathrm{pH}$ was adjusted to $\mathrm{pH} 7.4$ with $\mathrm{NaOH}$. The control (isosmotic) solution with comparable ionic compositions was prepared by supplementing the $70 \%$ hyposmotic medium with $80 \mathrm{mM}$ mannitol. The 80 and $90 \%$ hyposmotic solutions were prepared by adding each amount of mannitol to the $70 \%$ hyposmotic solution, 26.7 and $53.3 \mathrm{mM}$, respectively. The pipette solution contained (in $\mathrm{mM}$ ) $\mathrm{KCl} 140, \mathrm{MgCl}_{2}$ 2, EGTA 5, HEPES 10, and Mg-ATP 5 (pH 7.3 with $\mathrm{KOH}$ ). In some experiments, genistein $(50 \mu \mathrm{M}$, Sigma, St. Louis, MO, USA), forskolin (10 $\mu \mathrm{M}$, Sigma), and IBMX (3isobutyl-1-methylxanthine) $(100 \mu \mathrm{M}$, Sigma $)$ were employed in the external solutions, and sodium orthovanadate $(500 \mu \mathrm{M}$, Wako, Osaka, Japan) was included in the pipette solution. In other experiments, AMPPNP (5 mM, Sigma) was substituted for Mg-ATP in the pipette solution.

Statistical analysis. Numerical data are presented as means \pm SEM (for $n$ observations). Comparisons are made by using the Student's $t$-test and analysis of variance (ANOVA). Statistical differences were considered significant when $p<0.05$.

\section{RESULTS}

\section{Cell swelling enhances the homomeric KCNQ1 channel current}

Cell swelling during superfusion with hyposmotic solutions increases $I_{\mathrm{Ks}}$ in guinea pig $[10,13,22]$ and canine [19] ventricular myocytes. We first focused on the effect of hyposmotic stress on the homomeric KCNQ1 channel and compared it with that on the heteromeric KCNQ1/KCNE1 $\left(I_{\mathrm{Ks}}\right)$ channel. The representative whole-cell membrane current recordings were obtained from cells transfected with both KCNQ1 and KCNE1 (Fig. 1A and B), or KCNQ1 alone (Fig. $1 \mathrm{E}$ and $\mathrm{F}$ ), initially when superfused with the control solution (Fig. 1A and E), and subsequently while challenged with the $70 \%$ hyposmotic medium (Fig. 1B and F).

As previously reported $[15,16]$, the heteromeric KCNQ1/KCNE1 channel generated a slowly activating and noninactivating $\mathrm{K}^{+}$current, which is typical of cardiac $I_{\mathrm{Ks}}$ (Fig. 1A). In contrast, the homomeric KCNQ1 channel yielded a rapidly activating outward current much smaller in amplitude than that seen with a co-expression of KCNQ1 and KCNE1 (Fig. 1E; note that the scales for time and current amplitude are different between the upper and lower panels). Like the behavior of native $I_{\mathrm{Ks}}$ in cardiac cells, the time-dependent outward currents of the heteromeric KCNQ1/ KCNE1 channel increased during the hyposmotic challenge (Fig. 1B). The noticeable finding was that the same hyposmotic stress equally induced a comparable manner of augmentation in the homomeric KCNQ1 channel current (Fig. 1F).

The averaged steady-state $I-V$ relationships for the two KCNQ1-related currents in the multiple cells are illustrated in Fig. 1C and G. As for the heteromeric KCNQ1/KCNE1 channel, the respective normalized activation curves fitted to Boltzmann's equation obtained in the control and hyposmotic conditions were almost superimposed (Fig. 1D).

To confirm the close relationship between osmotic cell swelling and the resultant enhancement of the currents for the heteromeric KCNQ1/KCNE1 and the homomeric KCNQ1 channels, we separately examined the effects of various degrees of hyposmotic challenge on (1) the cell volume and (2) the two KCNQ1-related currents. Figure 2A shows the relationship between the hyposmotic stress and the corresponding incremental ratio of the cell volume. The magnitude of cell swelling was smaller in transfected cells expressing the heteromeric KCNQ1/KCNE1 channels than in those with the homomeric KCNQ1 channels or without exogenous channels in the 3 different hyposmotic conditions. There was no significant difference in the incremental ratio of cell volume between transfected cells with the homomeric KCNQ1 channels and those without exogenous ones.

Figure 2B summarizes the relations between various hyposmotic stress and the corresponding percent increase of current amplitude in the two KCNQ1-related channels measured at $+50 \mathrm{mV}$ during superfusion with each of the hyposmotic solutions. The greater hyposmotic stress resulted in the greater increase in each of the two currents, and there was no significant difference in incremental percentage of current amplitude between the two currents. 
A

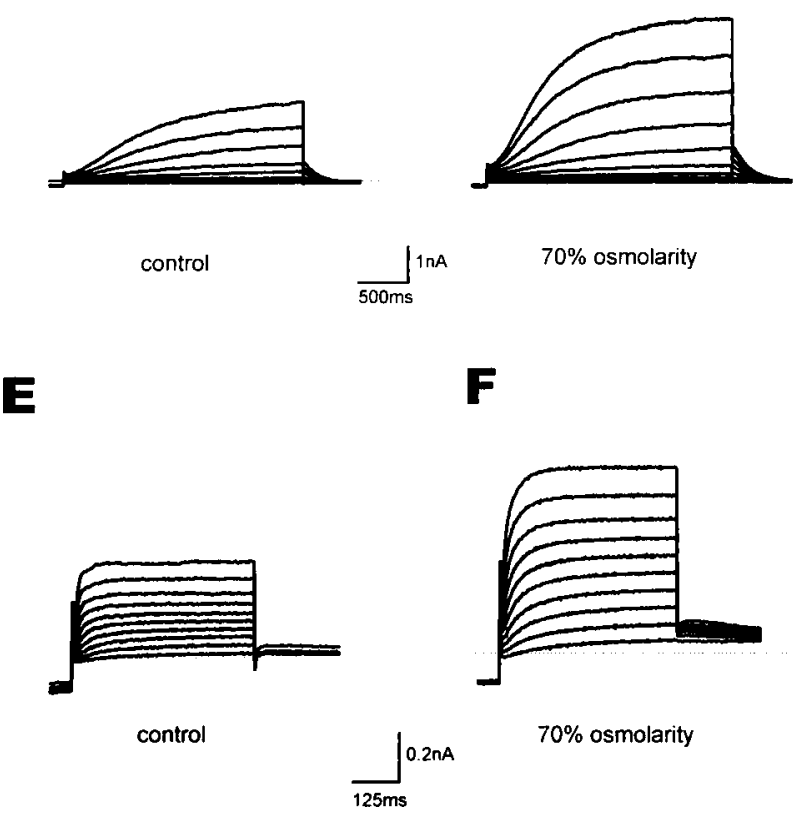

Fig. 1. Cell swelling enhances not only the heteromeric KCNQ1/KCNE1 channel current, but also the homomeric KCNQ1 channel current in COS7 cells. The currents for the heteromeric KCNQ1/KCNE1 channel (A and $\mathbf{B})$ and the homomeric KCNQ1 channel (E and $\mathbf{F})$ were recorded under the control solution ( $A$ and $E$ ) and during superfusion with the $70 \%$ hyposmotic medium (B and F). Depolarizing test pulses of different durations ( 2 or $0.5 \mathrm{~s}$ ) were applied in $10 \mathrm{mV}$ increments from -30 to $+40 \mathrm{mV}$, followed by a return to $-30 \mathrm{mV}$. In multiple transfected cells, the averaged steady-state $I-V$ relations for the former $(\mathbf{C})$ and the

\section{Is tyrosine phosphorylation a key step in the $I_{\mathrm{Ks}}$ enhancement by cell swelling?}

As stated earlier, an activity of PTK has been suggested to be responsible for the cell swelling-induced enhancement of $I_{\mathrm{Ks}}$ in canine ventricular myocytes [19]. Thus we employed pharmacological maneuvers that could modulate a putative PTK-mediated pathway pertaining to the $I_{\mathrm{Ks}}$ enhancement and thereby attempted to determine whether tyrosine phosphorylation and deposphorylation are key steps in the underlying mechanism.

At first, a broad spectrum PTK inhibitor, genistein, was used in this expression system as examined in canine ventricular myocytes [19]. Figure 3A illustrates a time course of changes in current amplitude of the heteromeric KCNQ1/KCNE1 channel measured at the end of 1-s test pulses at $0 \mathrm{mV}$. The exposure of a transfected cell expressing the reconstituted $I_{\mathrm{Ks}}$ channel to the $70 \%$ hyposmotic medium (HYPO) rapidly elicited about a twofold increase in the $I_{\mathrm{Ks}}$ current (Fig. 3A-a). Switching back to the control solution readily reduced it to its previous level, although there was a slight cur-

\section{C}
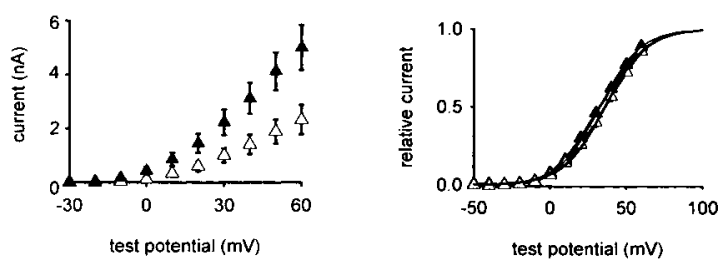

$\mathbf{G}$

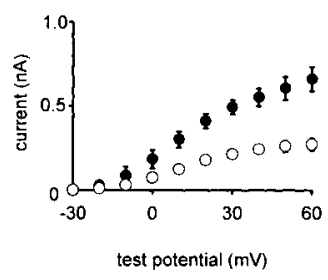

latter $(\mathbf{G})$ were measured from -30 to $+60 \mathrm{mV}$ under the control solution (open symbols) and the $70 \%$ hyposmotic medium (closed symbols). To determine the voltage-dependence of activation for the heteromeric KCNQ1/KCNE1 channel, the deactivating tail currents were used for analysis, and data points were fitted to a Boltzmann distribution using calculated maximum values (D). The half-activation voltage $V_{0.5}$ and slope factor $V_{S}$ are $35.8 \pm 1.7 \mathrm{mV}, 13.7 \pm 0.5$ $\mathrm{mV}$ in the control condition and $32.6 \pm 1.5 \mathrm{mV}, 13.4 \pm 0.3 \mathrm{mV}$ in the $70 \%$ hyposmolarity $(p=0.15, p=0.72$, respectively; $n=14)$.

rent rundown (Fig. 3A-b). A subsequent application of $50 \mu \mathrm{M}$ genistein resulted in a further reduction in amplitude (Fig. 3A-c). In the continuous presence of the PTK inhibitor; however, a re-exposure to the $70 \%$ hyposmotic medium unaffectedly augmented the $I_{\mathrm{Ks}}$ current (Fig. 3A-d). After being superfused with the control solution, a washout of genistein allowed it to regain the current level comparable to that in the absence of the drug (Fig. 3A-e). A challenge with the $70 \%$ hyposmotic medium was repeatedly able to produce about a twofold increase in the $I_{\mathrm{Ks}}$ current (Fig. $3 \mathrm{~A}-\mathrm{f})$.

If tyrosine phosphorylation is a key step in the cell swelling-induced $I_{\mathrm{Ks}}$ enhancement, the rapid reversibility of its amplitude upon removal of the hyposmotic challenge (e.g., see Fig. 3A, a $\rightarrow$ b) might be accounted for by a counteracting process of tyrosine dephosphorylation by PTP. On this assumption, the cell swelling-induced augmentation of the $I_{\mathrm{Ks}}$ current might be sustained as long as a concomitant activity of PTP is suppressed by its potent inhibitor, orthovanadate. 
A

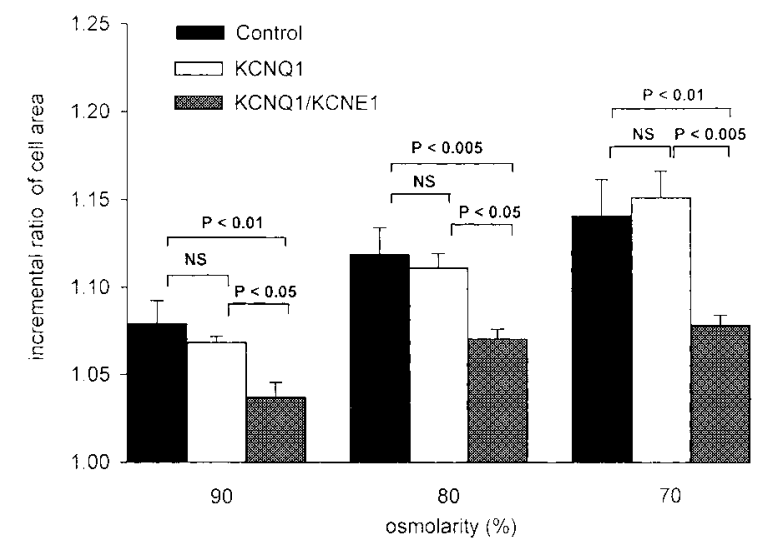

B

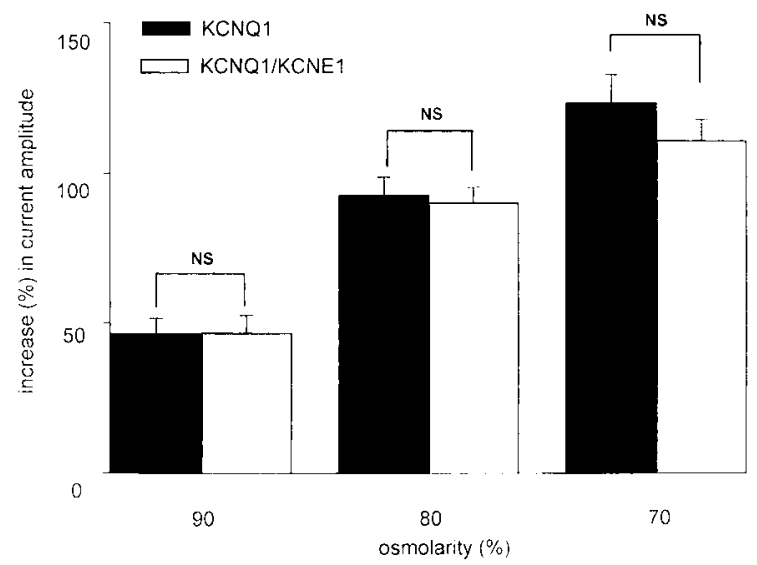

Fig. 2. Effects of various degrees of hyposmotic stress on the cell area and the two KCNQ1-related currents. The relationships between the various degrees of hyposmotic stress and the cell area are shown in the cells transfected with plasmid control $(n=10), \mathrm{KCNQ} 1$ alone $(n=8)$, or both KCNQ1 and $\operatorname{KCNE}_{1}(n=9)(\mathbf{A})$. The corresponding enhancement of the currents induced by the respective hyposmotic challenge are compared between the heteromeric KCNQ1/KCNE1 (90\%, $n=23 ; 80 \%, n=13 ; 70 \%$, $n=10)$ and the homomeric KCNQ1 channels (90\%, $n=19$; $80 \%, n=14 ; 70 \%, n=8)$ (B). The time-dependent currents were measured as the difference at the start and the end of 2-s test pulses at $+50 \mathrm{mV}$ from a holding potential of $-70 \mathrm{mV}$ before and during superfusion with various hyposmotic solutions, and the incremental magnitude is shown as a percentage.

As shown in Fig. 3B, however, intrapipette $500 \mu \mathrm{M}$ orthovanadate failed to sustain the hyposmotically induced increase of the current obtained during the $70 \%$ hyposmotic challenge. In contrast, its PKA-dependent augmentation lasted over 4 min even after a washout of two PKA activators, forskolin $(10 \mu \mathrm{M})$ and IBMX $(100 \mu \mathrm{M})$ (to the right of Fig. 3B). As previously re- ported [23], the latter part of the observation warranted that this concentration of orthovanadate was substantially effective in inhibiting not only PTP, but also phosphoserine/threonine phosphatases. As summarized in Fig. 3C, neither genistein nor orthovanadate appeared to affect the $I_{\mathrm{Ks}}$ enhancement by osmotic cell swelling.

From the above results, the cell swelling-induced $I_{\mathrm{Ks}}$ enhancement appeared very unlikely to depend on PTK activity. Since PTKs do not efficiently utilize hydrolyzable nucleotide triphosphates other than ATP as a phosphate donor for phosphorylation [24], we finally examined the effect of AMP-PNP, a nonhydrolyzable ATP analog that acts as a competitive inhibitor against ATP-dependent enzymes.

Figure 4A depicts a time course of changes in the current amplitude of the reconstituted $I_{\mathrm{Ks}}$ channel measured at the end of 1 -s test potential of $0 \mathrm{mV}$ in the continuous presence of $5 \mathrm{mM}$ AMP-PNP. The changes were observed initially in response to PKA stimulation and subsequently during a superfusion with the $70 \%$ hyposmotic medium. The PKA activators produced only a slight increase in the $I_{\mathrm{Ks}}$ current (to the left of Fig. 4A), indicating that AMP-PNP mostly blocked the PKA-dependent $I_{\mathrm{Ks}}$ augmentation (see Fig. 3B). In contrast, in accordance with the experiments in Fig. 3 the $70 \%$ hyposmotic challenge was seen to elicit about a twofold increase in the current despite the presence of this compound (to the right of Fig. 4A). Figure 4B summarizes the differential effects of AMP-PNP on the PKA-dependent and the cell swelling-induced $I_{\mathrm{Ks}}$ enhancement, suggesting that the $I_{\mathrm{Ks}}$ enhancement by cell swelling might not be associated with ATP-dependent phosphorylation.

\section{DISCUSSION}

Role of KCNQ1 in the cell swelling-induced $I_{\text {Ks }}$ enhancement. The initial goal of this study was to determine which of the two structural units of the $I_{\mathrm{Ks}}$ channel plays a key role in the cell swelling-induced $I_{\mathrm{Ks}}$ enhancement. We have shown that osmotic cell swelling augments the heteromeric KCNQ1/ KCNE1 channel current. This phenomenon is in agreement with the behavior of native $I_{\mathrm{Ks}}$ observed in guinea pig and canine ventricular myocytes $[10,13$, $19,22]$, though the cellular background is quite different between cultured heterologous cells and isolated cardiomyocytes. It remains unclear whether the phenomenon is ubiquitously seen in whatever type of cells the $I_{\mathrm{Ks}}$ channel exists; however, it would appear unlikely that intracellular components specific to cardiomyocytes are necessary for the $I_{\mathrm{Ks}}$ regulation. It is 
interesting that hyposmotic stress was equally capable of enhancing the homomeric KCNQ1 channel current. There was no significant difference in the incremental ratio of current amplitude in response to various hyposmotic challenges between the heteromeric KCNQ1/ KCNE1 and homomeric KCNQ1 channel currents. Our data suggest that KCNQ1 might primarily participate in the cell swelling-induced $I_{\mathrm{Ks}}$ enhancement.

In the present study, we further explored a possible involvement of tyrosine phosphorylation and dephosphorylation in the cell swelling-induced $I_{\mathrm{Ks}}$ enhancement in a heterologous expression system. The tyrosine kinase inhibitor genistein $(50 \mu \mathrm{M})$ [25] diminished the baseline amplitude of the $I_{\mathrm{Ks}}$ current; still it
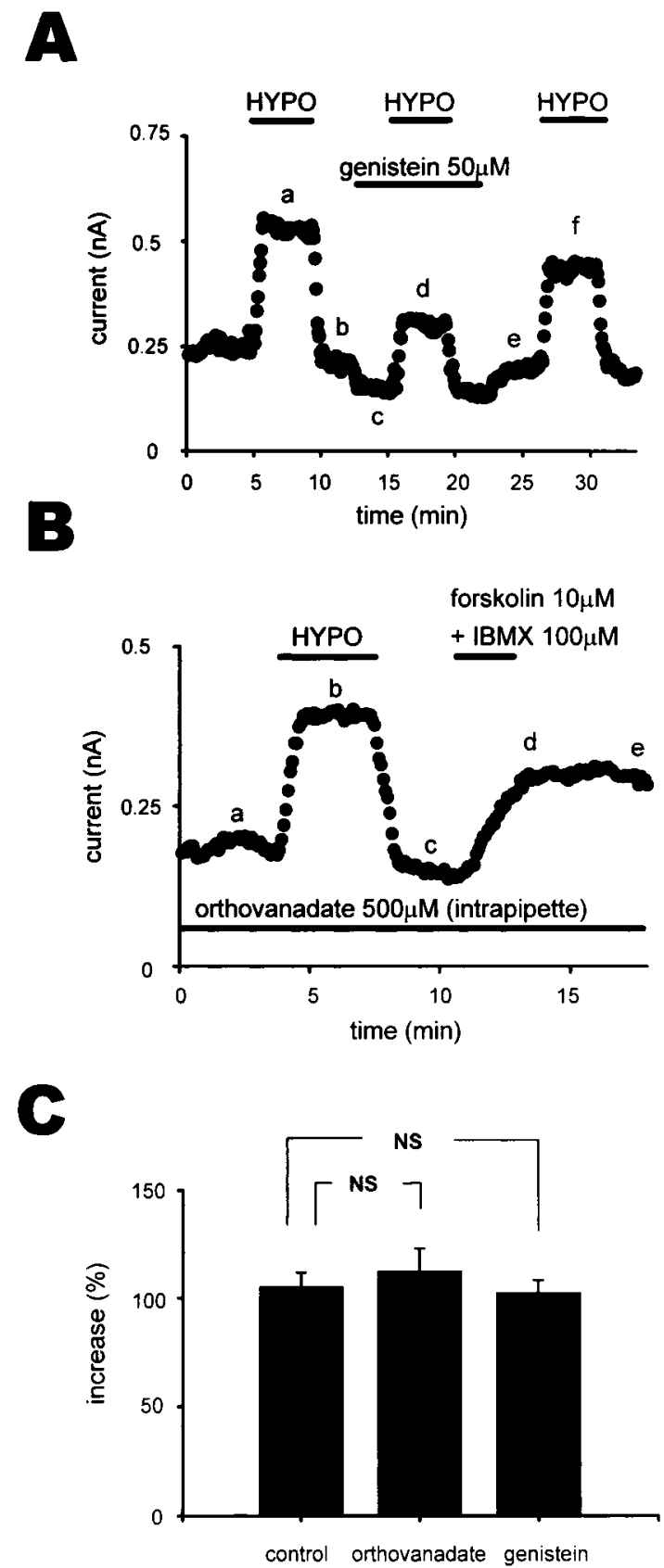

failed to completely abolish augmentation of the $I_{\mathrm{Ks}}$ by osmotic cell swelling (Fig. 3A and C). Our observations were apparently in contrast with those of Zhou et al. that the cell swelling-induced enhancement of canine $I_{\mathrm{Ks}}$ was totally blocked by the PTK inhibitor at the same concentration as the one tested in our experiments [19]. These results, however, might be due to differences in the expression system examined (cloned or native), experimental conditions, and perhaps species (human or canine). It is noteworthy that since genistein can reduce $I_{\mathrm{Ks}}$ activity independently of PTK in guinea pig ventricular myocytes [26], the additional action of the PTK inhibitor might have led to the apparent conflict of these results. The drug-induced suppression of the $I_{\mathrm{Ks}}$ in our preparations (Fig. 3A) was like that seen in canine ventricular myocytes [19]. To settle this issue, it might be helpful to examine the effects of other equally potent PTK inhibitors on the $I_{\mathrm{Ks}}$ enhancement.

Orthovanadate $(500 \mu \mathrm{M})$, widely used to enhance tyrosine phosphorylation, did not disturb the rapid reversibility of the $I_{\mathrm{Ks}}$ upon the removal of a hyposmotic challenge (Fig. 3B and C). AMP-PNP (5 mM) clearly failed to block the $I_{\mathrm{Ks}}$ enhancement by osmotic cell swelling (Fig. 4). This argues against a possible role of protein kinases, including PTK, which require ATP for their action as a dominant regulator in the $I_{\mathrm{Ks}}$ augmentation. Although it may be premature to conclude that neither ongoing phosphorylation nor dephosphorylation is involved in the cell swelling-induced $I_{\mathrm{Ks}}$ enhancement, its obligatory dependence on PTK activity remained to be demonstrated, at least in our

Fig. 3. Neither inhibitor of PTK nor PTP affects the $I_{\mathrm{Ks}}$ enhancement by osmotic cell swelling. A: Time course of changes in the reconstituted $/_{\mathrm{Ks}}$ current amplitude during superfusion with the $70 \%$ hyposmotic medium (HYPO) in the absence or presence of $50 \mu \mathrm{M}$ genistein. See the text for the definition of letters a to $f$ in this panel. B: Time course of changes in the current amplitude, initially during exposure to the $70 \%$ hyposmotic medium (HYPO), and subsequently during the application of two PKA activators, $10 \mu \mathrm{M}$ forskolin, and $100 \mu \mathrm{M}$ IBMX, in the presence of 500 $\mu \mathrm{M}$ orthovanadate. In both $\mathrm{A}$ and $\mathrm{B}$, the changes of timedependent currents are represented by the difference in current amplitude between the 2 values measured at the start and end of 1-s depolarizing steps to $0 \mathrm{mV}$ applied from a holding potential of $-70 \mathrm{mV}$. The pulse step was repeated every $5 \mathrm{~s}$. Periods of solution exchanges and an application of the drugs are denoted by horizontal bars. The definition of the letters a to e in this panel is also referred to the text. C: The effects of genistein and orthovanadate on the $l_{\mathrm{ks}}$ enhancement by osmotic cell swelling are compared between the control condition (left bar, $n=11$ ), $50 \mu \mathrm{M}$ genistein (right bar, $n=10$ ), and $500 \mu \mathrm{M}$ orthovanadate (middle bar, $n=10)$. 

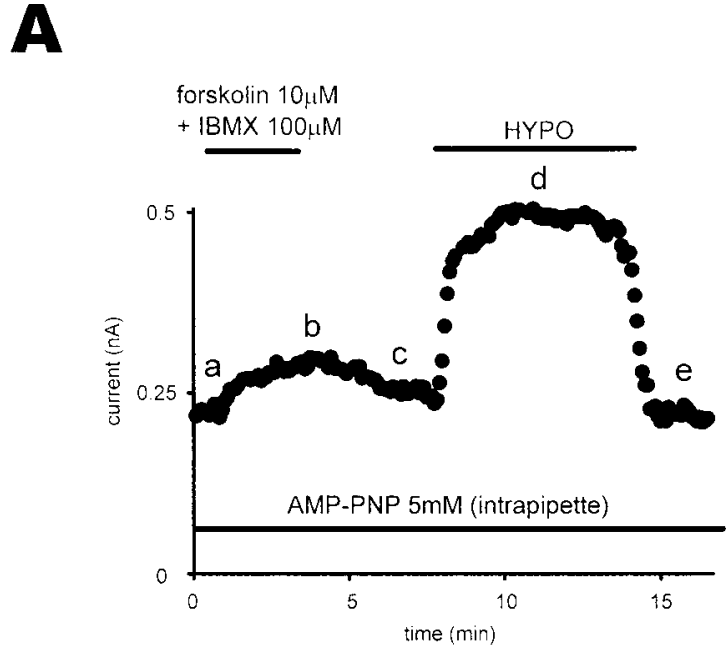

$\mathbf{B}$

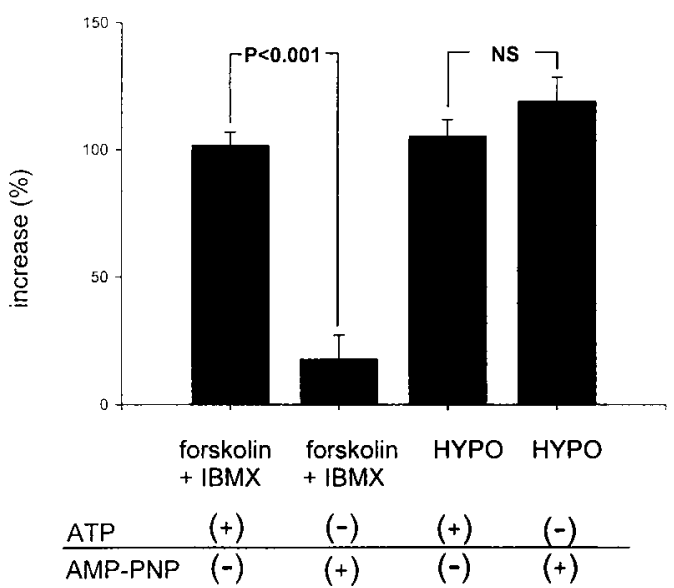

Fig. 4. No ATP-dependent phosphorylation is required in the cell swelling-induced $I_{\mathrm{Ks}}$ enhancement. A: A time course of changes in the $I_{\text {Ks }}$ current is observed, initially during the application of the PKA activators, and subsequently, during exposure to the $70 \%$ hyposmotic medium (HYPO) in the presence of $5 \mathrm{mM}$ AMP-PNP. The pulse protocol and recording intervals are the same as used in the experiment of Fig. 3, and the changes of time-dependent currents are represented by the difference in current amplitude between the 2 values measured at the start and end of depolarizing pulses. Horizontal bars denote the periods of exposure to the drugs and solution changes. The letters a to $e$ in this panel are defined in the text. $\mathbf{B}$ : The effects of AMP-PNP on the $I_{\text {Ks }}$ augmentation caused by PKA stimulation or osmotic cell swelling are summarized. Shown are percent increase in current amplitude induced by PKA stimulation (forskolin+IBMX) in the presence of ATP (left bar, $n=13$ ), and AMP-PNP (second bar, $n=9$ ), or exposure to the $70 \%$ hyposmotic medium (HYPO) in the presence of ATP (third bar, $n=11$ ), and AMP-PNP (right bar, $n=16$ ).

preparations.

Physiological and pathological implications of the cell swelling-induced $I_{\mathrm{Ks}}$ enhancement in cardiac cells. As shown in the experiments of
Fig. 2A, the cells expressing the heteromeric KCNQ1/ KCNE1 channel swelled less than those with the homomeric KCNQ1 channel or without exogenous channels. Several studies have shown that mammalian cardiac cells swell rapidly when exposed to hyposmotic media, but the reported data for volume regulation during a hyposmotic challenge in those cells are inconclusive [27]. Previous experiments in vestibular dark cells showed that the $I_{\mathrm{sK}}$ channel, a counterpart of the cardiac $I_{\mathrm{Ks}}$ channel, is volume-sensitive and that it might possibly be involved in the volume regulation of the cells during a hyposmotic challenge [28, 29]. In most cells, a regulatory decrease in cell volume is accomplished by the loss of potassium chloride released as inorganic osmolytes through separate potassium and chloride channels or the $\mathrm{K}^{+}-\mathrm{Cl}^{-}$cotransporter [30]. In the transfected cells examined here, the cell swelling-induced incremental percentage was not significantly different between the current for the heteromeric $\mathrm{KCNQ} 1 / \mathrm{KCNE} 1$ channel and that for the homomeric KCNQ1 channel. Nevertheless, there was an even larger net $\mathrm{K}^{+}$efflux in the cells expressing the former than in those expressing the latter, as indicated in measured current amplitude. The $I_{\mathrm{Ks}}$ channel might therefore be contributory to the volume regulation.

Moreover, COS7 cells most likely have swelling-activated $\mathrm{Cl}^{-}$channels [31]. In our experiments, the estimated equilibrium potentials for $\mathrm{K}^{+}\left(E_{\mathrm{K}}\right)$ and $\mathrm{Cl}^{-}$ $\left(E_{\mathrm{Cl}}\right)$ were about -87 and $+7 \mathrm{mV}$, respectively. Assuming that their resting membrane potential ranges between these two values, the opening of swelling-activated $\mathrm{Cl}^{-}$channels evokes an inward current as a result of the efflux of cytosolic $\mathrm{Cl}^{-}$from the cells. Although this current could contribute to a depolarization of the cell membrane, it would be offset by the concurrent $\mathrm{K}^{+}$efflux through the heteromeric KCNQ1/ KCNE1 channel that might re-establish the resting membrane potential.

The significance of cell swelling-induced $I_{\mathrm{Ks}}$ enhancement might be better understood under pathological conditions. During ischemia and reperfusion, cardiac cells have been shown to undergo significant swelling [32], which has marked effects on cardiac myocytes electrophysiology by modulating the function of several of salcolemmal ion channels and transporters [1]. In particular, the activation of $I_{\mathrm{Ks}}$ would promote the repolarization of cell membrane and the shortening of the action potential duration, thereby resulting in a decrease in the refractory period, which can contribute to the genesis of, or facilitate the perpetuation of, reentrant arrhythmias [33]. This implication is of more clinical importance because KCNQ1 may represent the more specific molecular target of 
the two subunits of the $I_{\mathrm{Ks}}$ channel for designing novel $I_{\mathrm{Ks}}$ selective antiarrhythmic agents that are more efficacious during myocardial ischemia and reperfusion.

We sincerely thank Dr. J. Barhanin for the gifts of KCNQ1 and KCNE1 clones, and Dr. A. Noma (Kyoto University, Kyoto, Japan) for his thoughtful discussion. This work was supported by a Grant-in-Aid on Priority Areas of ABC proteins (10217204) from the Japan Ministry of Education, Science, Sports and Culture.

\section{REFERENCES}

1. Vandenberg JI, Rees SA, Wright AR, and Powell T: Cell swelling and ion transport pathways in cardiac myocytes. Cardiovasc Res 32: 85-97, 1996

2. Kawata H, Kawagoe K, and Tateyama I: Effects of osmolarity change on the excitation contraction coupling of bullfrog ventricle. Jpn J Physiol 24: 587-603, 1974

3. Ehara T and Hasegawa J-I: Effects of hypertonic solution on action potential and input resistance in the guinea-pig ventricular muscle. Jpn J Physiol 33: 151-167, 1983

4. DeFelice LJ, Goolsby WN, and Mazzanti M: Potassium channels and the repolarization of cardiac cells. Ann N Y Acad Sci 588: 174-184, 1990

5. Tseng GN: Cell swelling increases membrane conductance of canine cardiac cells: evidence for a volumesensitive Cl channel. Am J Physiol 262: C1056-C1068, 1992

6. Van Wagoner DR: Mechanosensitive gating of atrial ATP-sensitive potassium channels. Circ Res 72: 973983, 1993

7. Whalley DW, Hool LC, Ten Eick RE, and Rasmussen $\mathrm{HH}$ : Effect of osmotic swelling and shrinkage on $\mathrm{Na}^{+}$$\mathrm{K}^{+}$pump activity in mammalian cardiac myocytes. Am J Physiol 265: C1201-C1210, 1993

8. Wright AR, Rees SA, Vandenberg JI, Twist VW, and Powell T: Extracellular osmotic pressure modulates sodium-calcium exchange in isolated guinea-pig ventricular myocytes. J Physiol (Lond) 488: 293-301, 1995

9. Sasaki N, Mitsuiye T, and Noma A: Effects of mechanical stretch on membrane currents of single ventricular myocytes of guinea-pig heart. Jpn J Physiol 42: 957970, 1992

10. Sasaki N, Mitsuiye T, Wang Z, and Noma A: Increase of the delayed rectifier $\mathrm{K}^{+}$and $\mathrm{Na}^{+}-\mathrm{K}^{+}$pump currents by hypotonic solutions in guinea pig cardiac myocytes. Circ Res 75: 887-895, 1994

11. Sanguinetti MC and Jurkiewicz NK: Two components of cardiac delayed rectifier $\mathrm{K}^{+}$current. Differential sensitivity to block by class III antiarrhythmic agents. J Gen Physiol 96: 195-215, 1990

12. Horie M, Hayashi S, and Kawai C: Two types of delayed rectifying $\mathrm{K}^{+}$channels in atrial cells of guinea pig heart. Jpn J Physiol 40: 479-490, 1990

13. Rees SA, Vandenberg JI, Wright AR, Yoshida A, and Powell $\mathrm{T}$ : Cell swelling has differential effects on the rapid and slow components of delayed rectifier potassium current in guinea pig cardiac myocytes. J Gen Physiol 106: 1151-1170, 1995
14. Wang Q, Curran ME, Splawski I, Burn TC, Millholland JM, VanRaay TJ, Shen J, Timothy KW, Vincent GM, de Jager T, Schwartz PJ, Towbin JA, Moss AJ, Atkinson DL, Landes GM, Connors TD, and Keating MT: Positional cloning of a novel potassium channel gene: KVLQT1 mutations cause cardiac arrhythmias. Nat Genet 12: 17-23, 1996

15. Barhanin J, Lesage F, Guillemare E, Fink M, Lazdunski M, and Romey G: KVLQT1 and IsK (minK) proteins associate to form the $I_{\mathrm{Ks}}$ cardiac potassium current. Nature 384: 78-80, 1996

16. Sanguinetti MC, Curran ME, Zou A, Shen J, Spector PS, Atkinson DL, and Keating MT: Coassembly of KVLQT1 and minK (IsK) proteins to form cardiac $I_{\mathrm{Ks}}$ potassium channel. Nature 384: 80-83, 1996

17. Lo CF and Numann R: Independent and exclusive modulation of cardiac delayed rectifying $\mathrm{K}^{+}$current by protein kinase $\mathrm{C}$ and protein kinase $\mathrm{A}$. Circ Res 83: 995-1002, 1998

18. Busch AE and Maylie J: Effects of calcium buffers and temperature on the receptor-mediated regulation of the slowly activating potassium current $\left(I_{\mathrm{ks}}\right)$ in guinea pig cardiac myocytes. Cell Physiol Biochem 4: 1-9, 1994

19. Zhou YY, Yao JA, and Tseng GN: Role of tyrosine kinase activity in cardiac slow delayed rectifier channel modulation by cell swelling. Pflügers Arch 433: 750757, 1997

20. Drewnowska K and Baumgarten CM: Regulation of cellular volume in rabbit ventricular myocytes: bumetanide, chlorothiazide, and ouabain. Am J Physiol 260: C122C131, 1991

21. Wang Z, Mitsuiye A, and Noma A: Cell distension-induced increase of the delayed rectifier $\mathrm{K}^{+}$current in guinea pig ventricular myocytes. Circ Res 78: 466-474, 1996

22. Groh WJ, Gibson KJ, and Maylie JG: Hypotonic-induced stretch counteracts the efficacy of the class III antiarrhythmic agent E-4031 in guinea pig myocytes. Cardiovasc Res 31: 237-245, 1996

23. Zhou SS, Takai A, Tominaga M, and Okada Y: Phosphatase-mediated enhancement of cardiac cAMP-activated $\mathrm{Cl}^{-}$conductance by a $\mathrm{Cl}^{-}$channel blocker, anthracene-9-carboxylate. Circ Res 81: 219-228, 1997

24. Hunter $T$ and Cooper JA: Protein-tyrosine kinases. Annu Rev Biochem 54: 897-930, 1985

25. Akiyama $T$ and Ogawara $H$ : Use and specificity of genistein as inhibitor of protein-tyrosine kinases. Methods Enzymol 201: 362-370, 1991

26. Washizuka T, Horie M, Obayashi K, and Sasayama S: Genistein inhibits slow component delayed-rectifier $\mathrm{K}$ currents via a tyrosine kinase-independent pathway. J Mol Cell Cardiol 30: 2577-2590, 1998

27. Deaton LE: Comparative aspects of cellular-volume regulation in cardiomyocytes. Physiol Zool 70: 379 390, 1997

28. Wangemann P, Liu J, Shen Z, Shipley A, and Marcus DC: Hypo-osmotic challenge stimulates transepithelial $\mathrm{K}^{+}$secretion and activates apical IsK channel in vestibular dark cells. J Membr Biol 147: 263-273, 1995

29. Shiga $N$ and Wangemann $P$ : Ion selectivity of volume regulatory mechanisms present during a hypoosmotic challenge in vestibular dark cells. Biochim Biophys 
Acta 1240: 48-54, 1995

30. O'Neill WC: Physiological significance of volume-regulatory transporters. Am J Physiol 276: C995-C1011, 1999

31. Ishii $\mathrm{T}$, Hashimoto $\mathrm{T}$, and Ohmori H: Hypotonic stimulation induced $\mathrm{Ca}^{2+}$ release from $\mathrm{IP}_{3}$-sensitive internal stores in a green monkey kidney cell line. J Physiol (Lond) 493: 371-384, 1996
32. Garcia-Dorado D and Oliveras J: Myocardial oedema: a preventable cause of reperfusion injury? Cardiovasc Res 27: 1555-1563, 1993

33. Wit $\mathrm{AL}$ and Coromilas $\mathrm{J}$ : Role of alterations in refractoriness and conduction in the genesis of reentrant arrhythmias. Implications for antiarrhythmic effects of class III drugs. Am J Cardiol 72: 3F-12F, 1993 